\title{
(Low) Expectations, Legitimization, and the Contingent Uses of Scientific Knowledge: Engagements with Neuroscience in Scottish Social Policy and Services
}

\author{
TINEKE BROER \\ University of Edinburgh \\ MARTYN PICKERSGILL ${ }^{2}$ \\ University of Edinburgh
}

\begin{abstract}
Neuroscientific research increasingly sparks the imaginations and hopes of policymakers. Whilst the diversity of assertive statements being made on the basis of neuroscience has been well documented, less frequently explored are more contingent discourses regarding studies of the brain. In this paper, we analyze how social policy and service actors discuss their engagements with neuroscientific terms, concepts and findings. These are mobilized, for one, to substantiate and enlarge the focus of existing policy-for example to attract funding for different target groups (such as babies, people who just retired, etc.) - as well as to help develop (new) policies and services. We show how, in so doing, invocation of the neurosciences can act to align "mutual imagined understandings" among policy actors, practitioners and parents. Tentativeness and ambivalence also figured within our respondents' accounts of the use of the neurosciences. They argued that research had to be simplified in order to make it relevant for wider stakeholders (including politicians), whilst simultaneously considering simplification problematic in some cases. Our analysis foregrounds the different complexities, ambivalences, reductions and instrumentalizations involved in policy and service engagements with the neurosciences, rendering challengeable any notion that (ideas about) neuroscientific research "determines" policy in a linear sense.
\end{abstract}

\section{Keywords}

neuroscience; social policy; expectations; contingencies; legitimation; STS

\footnotetext{
${ }^{1}$ Tineke Broer, Email: tineke.broer@ed.ac.uk

${ }^{2}$ Martyn Pickersgill, Email: martyn.pickersgill@ed.ac.uk

Copyright (c) 2015 (Tineke Broer and Martyn Pickersgill). Licensed under the Creative Commons Attribution Noncommercial No Derivatives (by-nc-nd). Available at estsjournal.org.
} 


\section{Introduction}

Neuroscience has fired the imaginations and expectations of policy actors internationally. Beyond the sphere of mental health, policy engagement with the brain has perhaps been most prevalent in initiatives around the first three years of life (often termed, "the early years"). In the UK, for example, findings and concepts from the neurosciences have been imported into policy debates and practice developments in order to emphasize the importance of the first three years of children's lives (a period where their brains are said to grow rapidly) (Broer and Pickersgill 2015; Macvarish, Lee, and Lowe 2014; O'Connor and Joffe 2013). These "early years" are framed as a "window of opportunity" in which interventions with and for parents and children can make a real difference to new lives, and there has been a rise in training courses for parents to capitalize on this.

The visibility of the neurosciences within UK policy has been documented extensively in recent years (Broer and Pickersgill 2015; Macvarish, Lee, and Lowe 2014; Wastell and White 2012; Edwards, Gillies, and Horsley 2015). A feature of much of this literature is a critique of policymakers, who are often regarded as misusing the neurosciences (Wastell and White 2012, 402; Edwards, Gillies, and Horsley 2015; Lowe, Lee, and Macvarish 2015a; Lowe, Lee, and Macvarish 2015b.) Rosalind Edwards and colleagues, for example, argue that "pseudo-scientific 'brain science' discourse is co-opted to bolster policy claims about optimal childrearing" (Edwards, Gillies, and Horsley 2015, 2). Scholars have also shown how a neurobiological idiom in parenting discourses can help to constitute a focus on individual parents rather than on the social and economic circumstances in which they find themselves. The result is that parents (especially mothers) come to be more anxious about raising their children (Macvarish, Lee, and Lowe 2015; Macvarish, Lee, and Lowe 2014; Wall 2004; Wall 2010).

In this paper, we develop work on the figuration of the neurosciences within policy, analyzing how actors involved in social policy and service communities in Scotland account for their (non-)use of neuroscientific notions and findings. Specifically, our analysis addresses two main questions. First, how do different actors account for the mobilization of neuroscience for policy and services? Second, what role do expectations, contingencies and legitimations play in these accounts?

\section{Conceptual Background}

In order to respond to the questions above, we take analytic cues from three key literatures: (1) on (low) expectations, (2) on discourses of contingency and hope in scientific talk and talk about science, and (3) on the political use of expert knowledge. With regard to the first, sociologists of expectations argue that "analyzing the dynamics of expectations is a key element in understanding scientific and technological change" (Borup et al. 2006, 286). Technoscientific expectations are a way of attracting and synthesizing different kinds of capital in a world that increasingly wants to know upfront what the societal impact of research will be. Such expectations help enroll different actors, including universities and patient organizations, in the quest for innovation, but they also pave the way for strong 
disappointment later on (Brown 2003). Expectations are performative, i.e., they co-produce the future they deal with by enabling "some technoscientific worlds, and disabl[ing] others" (Brown and Michael 2003, 14).

Aside from the highly promissory discourses that initially secured the attention of STS scholars (Brown 2003; Martin, Brown, and Kraft 2008; Martin, Brown, and Turner 2008; Brown 2005), low expectations have also been the subject of scholarly examination. While they do not use the term "sociology of expectations" per se, Moreira and Palladino (2005) can be considered to have provided an analytic platform for studying low expectations. They regard biomedicine as encapsulating both a "regime of hope" that is "characterized by the view that new and better treatments are always about to come" (p. 67) and "a regime of truth" that is situated in what is positively known, including how hopes can lead to disappointment and failure. Low expectations, then, are generally situated in a regime of truth (Gardner, Samuel, and Williams 2015) and they have been analyzed in different forms; for example, the pessimistic and cautionary claims made by industry actors (Tutton 2011), the modification of patient expectations (Gardner, Samuel, and Williams 2015), and the dialectic between hope and skepticism about the translation of neuroscience into clinical practice (Fitzgerald 2014; Pickersgill 2011). With regard to the latter, Fitzgerald attributes the low expectations evident within his data in part to the "private, reflective and conversational mode of sociological intervention," i.e., interviews with researchers wherein they felt able to reflect carefully and candidly on the possibilities and problems of (translational) research (Fitzgerald 2014, 258).

Earlier scholarship, which in some senses anticipated the work of both Fitzgerald and Moreira and Palladino, has likewise shown how scientists draw on different, seemingly contradictory, repertoires. In particular, the path-breaking work of Gilbert and Mulkay (1982) explores scientists" use of both "empiricist" and "contingent" repertoires in accounting for their beliefs. The former repertoire is one in which data is presented as determining truth; the latter, on the other hand, "depict[s] the relationship between fact and theory in a much more contingent matter" (p. 400). In contingent repertoires, facts depend on interpretation. Scientists draw flexibly upon these two repertoires at different moments and in varying contexts. In later work, Mulkay analyzed how scientific research is employed within political debates, showing that hope and fear were rhetorical devices adopted in UK parliamentary debates on the control of conduct in research on human embryos (Mulkay 1993). Both of these studies are helpful as a framework for understanding contingencies and ambivalences regarding the normative and intrinsic significance of (biomedical) research (see also Kerr and Cunningham-Burley 2000; Kerr, Cunningham-Burley, and Tutton 2007), as well as the relationship between science, policy and society. Specifically, Gilbert's and Mulkay's work indicates how tentativeness and certitude, hopes and fears, can co-exist and be employed to strategic ends.

This point also connects to the last key strand of literature we draw upon, which more directly investigates the political use of expert knowledge. Boswell (2008), for example, argues how knowledge utilization in politics can have an overtly instrumental function to adjust policies, as well as serving a symbolic function. This latter role includes the substantiation of policy preferences, and the legitimization of (the work of) organizations by 
"endow[ing] [them] with 'epistemic authority'" (p. 472). Where Boswell has investigated the way policy actors use knowledge, other scholars have looked at how scientific advice gets constructed (by scientists) in such a fashion as to assist in decision making in contested political issues. Such scholars have argued, for instance, that the means through which scientific research comes to be collected and negotiated is a "backstage" process that can differ extensively from the "frontstage" process of presenting and using the science for and in policy (Bijker, Bal, and Hendriks 2009; Hilgartner 2012; Hilgartner 2000).

Accordingly, it seems that contingencies and different repertoires (or "frontstage" and "backstage" processes) are constitutive of the relations between policy and research, and scientists especially have been shown to articulate divergent discourses when talking about their work and beliefs. With regard to how neuroscience has been used in policies and services, focus has predominantly rested on the visibility of brain research (and the facticity with which it is imbued). This might, in part, result from a methodological emphasis on documents. Where studies have been concerned with the "frontstage" of policy, this is, of course, entirely appropriate. Yet, in attending explicitly to public-facing documents in analyses of neuroscience, policy and society, social scientists (including ourselves, see Broer and Pickersgill 2015) may implicitly be constructing an understanding of policy and service communities that renders the individuals that comprise them as being more epistemologically and normatively certain than in fact they are. Exploring policy actors' reflections in interviews regarding their own and others' engagements with the neurosciences can, we believe, cast a bright light on how contingencies and uncertainties operate within the discursive worlds of policy and service design and delivery.

\section{Neuroscience in Policy and Practice}

We draw on insights from the literatures discussed above in order to analyze how a range of actors account for the use of neuroscience in policies and services. Our data (discussed more fully below) comes from 11 interviews conducted in Scotland in 2014. By examining our respondents' discussions of "scientific research" (which we understand here both as actual specific scientific articles and findings, and an imagined and assumed neurobiological "canon"), we adopt a "symmetrical" position common in the sociology of scientific knowledge (SSK) (Bloor 1991) and other traditions within STS. Accordingly, we diverge from the interests of some other authors concerned with neuroscience and policy (for example, Macvarish, Lee, and Lowe 2014; Wastell and White 2012; Edwards, Gillies, and Horsley 2015). Our principal concerns lie neither with the accuracy of our respondents' understandings of neuroscience, nor the appropriateness of the uses to which it is put. Rather, we are interested in the question of whether neuroscientific research is salient to our respondents, and, if so, how.

Our contribution to the STS literature through this paper will be threefold. First, we will contribute to discussions around (low) expectations by considering them within policy discourse (rather than within narratives emerging from healthcare settings, scientific institutions, or industry (Gardner, Samuel, and Williams 2015; Tutton 2011; Fitzgerald 2014; 
Pickersgill 2011)). Second, our analysis will augment literatures concerned with the ways in which different actors draw on (neuro)science for policy and service design and delivery (Broer and Pickersgill 2015; Edwards, Gillies, and Horsley 2015; Lowe, Lee, and Macvarish 2015a; Lowe, Lee, and Macvarish 2015b) especially through underscoring the ambiguities and uncertainties present in their accounts. Third, this paper enhances empirical specificity concerning the impacts and translation of neuroscientific knowledge in contemporary society (Bröer and Heerings 2013; Buchman et al. 2013; Pickersgill 2013; Pickersgill et al. 2015; Rose 2007; Rose and Abi-Rached 2013; Singh 2013; Vidal 2009; Vrecko 2010).

\section{Methods}

This research forms part of a larger Leverhulme Trust-funded project ("Neuroscience and Family Life: The Brain in Policy and Everyday Practice"), which investigates how the neurosciences are (not) engaged with in different contexts, including in policy, the media, and domestic spheres. The strand of the study presented here analyzed engagements with brain research by actors involved in policy-making communities. We conducted 11 semi-structured interviews with Scottish policy and practice actors working in three key areas: the early years, adolescence, and older adulthood. Each are life stages for which their associated biological and cultural markers have been discussed in terms of (changes in) the brain (Broer and Pickersgill 2015; Choudhury, McKinney, and Merten 2012; Pickersgill 2014; Williams, Higgs, and Katz 2012).

We deliberately aimed for a diverse sample, to try and capture wide-ranging experiences with how concepts and findings from the neurosciences (might) impact and shape social policy and services. We began by speaking informally with people who have contacts in the Scottish and local government and social services, which resulted in a "longlist" of about 50 people. We then selected a "short-list" of key individuals in various policy domains and "levels" (e.g. local versus national), including people involved in influencing policy, formulating policy, and translating policy to social services. Our final respondent list included people working in different sectors (i.e., statutory and voluntary), reflecting our understanding of policymaking communities as not solely restricted to politicians and civil servants (Smith and Katikireddi 2013). Our respondents were, for instance, directors of charity organizations or heads of local authority or national departments (i.e., local government worker, national government worker), as we expected such individuals to have an overarching perspective on the dynamic relationships between research, policy and practice. Their roles were likewise wide-ranging. ${ }^{3}$

Whereas most of the work in the UK on the impact of the neurosciences on policy has been concerned with England, Scotland is also important to consider. In Scotland, policies and practices from England impact and shape agendas and innovations-at the same time, Scottish developments can and do contour those in England. While Scottish policy is arguably

\footnotetext{
${ }^{3}$ Table 1 provides more information on our respondents, although in order to protect their anonymity we cannot be very specific.
} 
developing its own "style," we suggest that our key findings can nevertheless be generalizable given the broad similarities between processes of policymaking and implementation across the UK (Cairney 2008; Cairney 2011). As our interviews took place right before and after the referendum concerning whether Scotland should become formally independent from the rest of the UK (held on September 18, 2014), this context will certainly

\begin{tabular}{|c|c|c|}
\hline & Role: & Life stage focus: \\
\hline 1 & Principal Officer, Scottish Local Authority & Early years/adolescence \\
\hline 2 & Senior Officer, Scottish Local Authority & Older adulthood \\
\hline 3 & Director, Scottish Charity & Early years \\
\hline 4 & Member, Voluntary Parent Organization & Primarily adolescence \\
\hline 5 & Project Manager, Scottish Voluntary Organisation & Early years and adolescence \\
\hline 6 & Head of Research, International Charity & Older adulthood \\
\hline 7 & Representative, Scottish Charity & Older adulthood \\
\hline 8 & Policymaker & Early years \\
\hline 9 & $\begin{array}{l}\text { Former Senior Civil Servant, Scottish Government/Officer, } \\
\text { Scottish Charity }\end{array}$ & Primarily early years \\
\hline 10 & Policy Advisor & Primarily early years \\
\hline 11 & Scottish Director, UK Children's Charity & Primarily early years \\
\hline
\end{tabular}

Table 1: Interview respondents

have contoured the tone and content of the interviews. However, we do not want to overplay the impact of the referendum on our participants' talk (and the practices and processes communicated therein). In particular, only two respondents explicitly mentioned it. We suggest that the referendum shaped our interviews through the impacts of its associated campaigns on the discursive space within which ideas about "the good society" could be considered and rehearsed. Hence, our respondents may have been more willing (and able) to articulate their concerns and hopes for the future than they would otherwise have been.

The interviews were conducted by Broer between July and November 2014. With appropriate consent, all were audio recorded and transcribed for analysis. We had expected each interview encounter to last less than an hour, since we did not anticipate that our busy respondents would be able to grant us a larger diary slot than this. Yet, most spoke much longer than an hour. This, we suggest, reflects the salience of the topics under discussion for our interviewees, as well as their appreciation of the opportunity to reflect on these issues. An interview guide was employed, which was designed to prompt participant talk around their role in social policy and/or services, the relevance of the neurosciences for their policy area(s), and the possible benefits and risks associated with using neuroscientific knowledge for policy and services. Following the production of a draft of this article, we sent the quotes that we wanted to use to the respondents for their approval. Two of the seven respondents

"The recorder failed halfway through interview 5. Immediately after the interview, Broer wrote up notes from the interview mostly based on memory. 
(Respondents 1 and 8) whose interview data we quoted suggested small changes to enhance legibility and coherence.

The completed interviews were rather varied in terms of tone and content. Following initial interrogation and discussion of the data separately and together, we pursued our analysis by writing narrative summaries of the interviews, in order to elucidate the themes that felt most resonant across the transcripts (Ross, in press). Four themes best captured the engagements with the neurosciences that were the stimulus for the interviews, and the ostensive focus of the discussions. These were: (1) hope and the hope to change; (2) tentativeness and awareness of simplification; (3) the capacity of the neurosciences to substantiate existing policies and ideas and to help develop policies; and (4) the necessity and the right of the state to intervene in the lives of its citizens. The fourth theme we saw as generally overarching in nature, encompassing most of the other three themes. The transcripts were then coded with NVivo software, using the four themes as codes, with additional codes created to incorporate other relevant content. We do not explicitly structure our paper as an exegesis of these group codes; rather, we use them (and especially our initial key themes) as a guide for the ensuing narrative, which seeks to make a conceptual and empirical contribution to understanding the use of (neuro)science in policy and services.

In what follows, we first show how neuroscientific knowledge is employed to imbue policies and practices with epistemic authority; we then proceed to describe more fully the often instrumental, commonly reflexive and sometimes cautious engagements of our respondents with neuroscience for policy and service design and delivery. Though appropriate to our study questions and context, our representational interview strategy, based on policy design and implementation in a small country, means that we conclude on a somewhat contingent note of our own: we are a little reluctant to make bold, universalizing claims about the nature of science and policy. Nevertheless, we feel that our central arguments-around the different complexities, expectations, ambivalences, and instrumentalities inherent to the use of (neuro)science in social policies and services, and hence the difficulties of ascertaining clear determinacies-are likely to find their equivalents in other contexts and nations.

\section{Epistemic Authority}

In this first section, we show how the neurosciences were seen to be used as a means to substantiate policies, especially in terms of granting these "epistemic authority" (Boswell 2008) and, hence, for securing funding for (proposed) services. In particular, our interviewees considered that neuroscientific concepts and findings could provide further (and compelling) justification for changes that they felt ought to be made anyway-policy changes aimed at impacting, for example, inequalities, parenting styles, and (un)healthy lifestyles.

Narratives of hope (particularly hope for societal change, a major theme within civil society discourse at the time of the interviews), and also of its absence, were prominent in our 
interviewees' talk. ${ }^{s}$ Such narratives related to stories of dissatisfaction: respondents were concerned about budget cuts, inequalities, children being fed unhealthy food, older people being discriminated against, and about people feeling overly guilty regarding their parenting practices. Respondent 10, for example, described society as a "disgrace," with widening inequalities and "people who can't afford to eat for three or four days a week." Respondent 9 also expressed his worries about society, for instance by speaking of his concern for serviceusers' "level of ignorance" regarding the raising of their children, and which somehow "we've got to try and turn around." He, as well as other respondents, saw the neurosciences as a way of understanding a world that concerned him, helping to enjoin action:

I mean, I suppose from the early years' perspective one of the strongest drivers for promoting early years and getting politicians of all parties on side was the evidence about the development of the child's brain from conception through the womb to birth [...] The impact of stress related hormones and chemicals on the child's development. The impact of neglect, abuse on a child's brain development.

Respondent 3, who occupied a senior role in a Scottish charity, described how in policies relating to young children, neuroscientific research "keeps us a bit more on track in terms of what is it that we're trying to do." All respondents working in the early years agreed that neuroscientific findings had helped to increase funding for services in this area, in part by confirming findings of other disciplines such as the social sciences—or, indeed, by providing a firmer epistemological footing for "common-sense" ideas about care and love. Respondent 1 , working for local government and involved in pulling together and writing courses for parents, discussed this:

I think that actually changed, that it wasn't just that it was nice to be loving and kind and supportive and talk to children and interact with them. It was nice, but actually what the researchers were saying, what they put to the debate is that, it's essential for development. It's essential for physical and physiological and neuronal development. I think it was the kind of, well you can't squeeze out of that, if everybody is saying the same thing, including the scientists, the neuroscientists, then I think it that's why it's become part of policy now. That's why there's getting it right for every child, that's why there's Curriculum for Excellence [a program in Scottish educational policy], looking at social and emotional wellbeing, that's probably why we have been funded, do you know what I mean?

Respondent 7, who occupied a senior role in a charity concerned with older adulthood and whose function in part is to influence policy and translate policy into services, argued that any charitable venture associated with children or cancer would be more likely to obtain funding since "it tugs the heart strings more." Yet, neuroscientific findings on how to prevent

${ }^{5}$ Most of the respondents were, to different degrees, directly involved in using the neurosciences for their policies and /or services (such as by reading studies, selecting the research, and helping to determine the possible consequences and practical implications for policy), though generally they talked from a more collective, organisational perspective, often by using the word 'we'. 
cognitive decline and improve healthy ageing helped his organization to successfully plead for funding too. In his words, "the research helps us because that helps support the reasoning and potential for change."'

Respondent 10 explicitly and strategically invoked neuroscientific findings within policy discussions to plea for substantive changes to governance in order to address what he regarded as inadequate policy responses to inequalities:

[I]n trying to bring some science to this, I'm trying to move the argument...it's all very well for me saying, "it's disgraceful," there's hundreds of other people out there who are saying "it's disgraceful." But I'm saying, "actually, the disgraceful way you treat the poor people means their families are fractured, and it means generation after generation is growing up to have problems [due to the reproduction of neurobiological impairment]. So stop it!"

Respondent 10 further maintained that "the harder the science the better" in order to convince politicians and society in general. Echoing social scientific reflections that have underscored the potency of neuro-images (Dumit 2004; Joyce 2005; Cohn 2004), he reflected:

Well you know, if you tell a society that the way in which they nurture children changes the way their brains develop, and you show them pictures that corroborate that, it's pretty compelling. No one wants to damage a child's brain, or to deny a child the opportunity to develop their brain properly. It's emotive, and it's powerful.

According to Respondent 10, the "hard" neurosciences have greater political traction than "soft" psychological research (for example), which is "always a bit hypothetical." To this end, he used brain research in presentations for a range of actors including policymakers. Respondent 9, who had attended some of these talks and was a civil servant at that time, argued that the research addressed in Respondent 10's presentations was "a great unifier." Later on in the interview he explained:

I like evidence-based policies and I like being able to explain and defend things on the basis of: here's the child's brain size at x months in a nurtured loving household. Here's a child's brain at the same age in a neglected household and it's half the size.

\footnotetext{
' In general, the use of the neurosciences in policies on older adulthood seemed to be looked at in an unequivocally positive way in contrast to those on early years. The three people we interviewed who were involved in shaping policy for older adults all had existing relationships with one of our study coinvestigators, who is involved in neuroscientific research. Positive aspects of the neurosciences and the influence of brain research on policy may thus have been especially emphasised in these interviews. On the other hand, journalistic and social scientific critiques of the 'misuse' of the neurosciences have been mostly targeted towards early years policy, so criticism would perhaps have been less likely to come up in the interviews around older adulthood since a visible critical discourse was not easily available for deployment within the interview talk. Further, the neurological challenges of ageing have emerged as a key social problem in the UK, and so the aligning of issues faced by older adults with changes in the brain is a relatively unproblematic stance for our interviewees to assume.
} 
Our interviews with Respondents 9 and 10, then, highlight not just the currency of scientific research within policy, but also the diverse values different epistemologies have within policy contexts (with the neurosciences coming to occupy a place of enhanced objectivity relative to more established modes of study). The interviews also show how mobilizing the neurosciences can be implicitly aimed to connect policy actors and align them around particular goals based on "mutual imagined understandings" (Martin, Brown, and Kraft 2008, 38).

The way the neurosciences at once substantiate and change policy was also discussed in the interview with Respondent 8. He was involved in reshaping the Scottish policy architecture for looked-after young people (i.e., children in care, such as foster homes), and argued that the neurosciences give policymakers an understanding of when, why and how to intervene, for example with respect to adoptions:

\begin{abstract}
We would talk about the language of aspiration. So we would say that brain science would tell us that, for an adoption to be successful, the child should be as young as possible. The reason for that is that they have the best chance of re-attaching to a new parent, with the least amount of, sort of, well I suppose the least amount of effort, if you like, on the part of the adopter [...] So without the neuroscience, you know, it would have been hard for us to make the case for change. It would have been hard for us to credibly tell social work: you need to do something different.
\end{abstract}

The ambiguous nature of the use of science in policy is underscored by Respondent 8's comments: whilst neuroscience "tells" policy actors how services should be organized, it also acts to make planned changes "credible." This then suggests (in Boswell's idiom) that neuroscience can be used both for overtly instrumental reasons and for more symbolic purposes (i.e., when it is aimed at legitimizing or substantiating policies) (Boswell 2008). One corollary of this, we suggest, is a need to be cautious in any claims-making around the extent to and manner with which neuroscience "determines" policy.

To summarize, in this section we have shown how some respondents saw the use of the neurosciences for a substantiation of policy as what we might call an "obligatory rhetorical passage point" (cf. Callon 1986) in order to secure different kinds of capital to support new or existing policy initiatives, nationally or locally, that might improve society. The future, as imagined in terms of risks to, for example, brain development, is "mobilized in the present" (Brown 2003, 5). Because of "mutual imagined understandings" (Martin, Brown, and Kraft 2008, 38) of the import of neurobiological health and impairment, early interventions or prevention are key terms in policy actors' accounts. Such ventures (e.g., early years intervention) seemed to encapsulate particular imaginaries of a "good society" and a certain hope regarding the possibility of effecting societal transformations. 


\section{Cautious Engagements}

Despite all of the respondents' sense that the neurosciences were important, their views varied with respect to the substantiation of (especially) early years policies through the neurosciences. The interviewees discussed in the previous section were generally positiveor at least fairly neutral-about using the neurosciences in part symbolically for policies. In this section, though, we will show how some respondents were more critically or cautiously engaged with neuroscientific research.

One of the main tropes in the interview with Respondent 5, for example, was a slightly critical stance towards the use of neuroscience as a "justification" for policy that gradually became apparent through the interview:

It's interesting isn't it because thinking about it, I think it's used as a justification. How much it actually influences what people do anyway or actually changes practice from what people were doing in the first place, I'm not altogether sure. People feel more often...I mean, there's more and more use of parenting programs and a lot of them are not, I don't think they would be primarily based on the neuroscience, but they may well use neuroscience as a kind of reason to use their programs more now.

This justification has been the case for the early years, according to Respondent 5, but she saw the neurosciences also increasingly being used to back up policies and services around teenagers and supporting parents of teenagers. Whereas this interviewee argued that we might learn from the neurosciences-like about adjusting school schedules based on recent findings concerning circadian rhythms of adolescents that are said to differ from those of adults-she thought that they are now often used for "social engineering," where "middle class values" were being "imposed" on "poor parents" (i.e., parents living in poverty). This resonates with critiques of "intensive parenting" advanced by some sociologists and social policy scholars (Lee 2008; Lowe, Lee, and Macvarish 2015b; Macvarish, Lee, and Lowe 2014; Macvarish, Lee, and Lowe 2015; Edwards, Gillies, and Horsley 2015; Wall 2004; Wall 2010). Respondent 5 furthermore reflected on why the neurosciences are used in policies, instead of (or in different ways than) the social sciences:

The problem for me in some ways with social policy is we accept that social sciences are inexact sciences, but we...generally a lot of social scientists and people whose backgrounds in the arts, accept that science is like the Bible, except the Bible is not taken verbatim now. They have a trust in science that they don't have in social science and rather than having the emphasis on, say, relationships or how we behave towards each other, there's a tendency to put the trust in something that's scientific and that we can "prove" that works [...] And I think from my understanding of it and what I've read it is very much an emerging field and we treat it on a really simplistic basis.

When asked why this might be the case, she answered: 


\begin{abstract}
Because I think people don't understand it and the kind of almost top line, bottom line, you know, it's almost like having that graph or having those few lines is enough. What they're interested in and rightly, is what you can do in the early years and then this is just used as a justification [...] If you're not scientific or you haven't gone down that route at school, I think [...] it may be difficult to understand and people actually don't want to go into neuroscience and that understanding because their interest is somewhere else. Their interest is in early years.
\end{abstract}

In spite of her complaint that policymakers did not engage sufficiently with scientific complexity, as a policy actor herself she nevertheless revealed how at least some who are involved in service design and delivery are aware of the difficulties inherent in interpreting the import of "an emerging field" of science. This suggests the existence of different, seemingly contradictory narratives in discourses surrounding and constituting policymaking and service delivery regarding the early years (Gilbert and Mulkay 1982).

Respondents did not reserve such criticisms for private interviews with us. Some of them reported to be actively involved in correcting misunderstandings of the neurosciences within policy and services. Respondent 1 , who was involved in making courses for parents and teachers of children and teenagers, evoked neuroscientific research on plasticity when she stated:

Not only is it really helpful in making you reflect on your parenting or your professional practice. It's very hopeful, the great news about all of these different research, I think is that it's really, really, hopeful, because what it's saying is, just because a child's had a difficult start in life doesn't mean that's going to be them for the rest of their lives. The brain can and does change in response to subsequent experiences. It says that even if a child maybe is more sensitive or more, you know, or has various different risk factors, relationships can make a difference. Even if you've already got good relationships, changing and improving that in your communication styles will have better outcomes for the future.

Respondent 1 also reacted against the idea that the brain stops developing at age 3 :

But, the idea that it's all or nothing by then there is absolutely immense research to say that's not the case. Especially given resilience research, and what we now know about the adolescent brain and how that goes through its massive period of remodeling. So, I think I can understand why some people are very cautious about the use of neuroscience being inappropriately used. But I think that fatalistic thing isn't backed up by research, so I think that's what's exciting, but it is sometimes misinformed, and we have sometimes gone to early years establishments, we do training in early years establishments and have asked people "who thinks that the brain stops developing at three" and people put their hands up, but that is why it is important to do this kind of training with them to combat these myths.

Hence, new neuroscientific research is made use of to correct the "misinformed" views of staff who are only familiar with apparently outdated ideas about the brain-notions which 
have also been critiqued in sociological and social policy literatures (see Lowe, Lee, and Macvarish 2015a; Lowe, Lee, and Macvarish 2015b; Macvarish, Lee, and Lowe 2014; Macvarish, Lee, and Lowe 2015; Wastell and White 2012).? This keenness to correct suggests an on-going engagement by some policy actors with different kinds of research into the brain and the psyche that complicates attempts to characterize "the" way that the neurosciences influence social policy and service provision. The somewhat more cautious engagements with neuroscience characterized above are indicative, we suggest, of a kind of "contingent" repertoire (about how the neurosciences are and should be used in policy and services) that nevertheless draws on a more "empiricist" register in terms of the facticity of (different) scientific studies (cf. Gilbert and Mulkay 1982).

\section{Pragmatic Reductionism}

Above we showed how some respondents were aware of a tendency to simplify research within policymaking communities (and on occasion were wary of doing so). Other interviewees argued that this is almost inherent in and necessary for policymaking (see also Shackley and Wynne 1996; Stevens 2011). In this section, we borrow a term from Beck and Niewöhner (2006, 223) and analyze this position as a kind of "pragmatic reductionism," which we define here as the translation of complex research findings into a coherent, straightforward message designed to enjoin practical action.

For example, Respondent 3 (a very senior representative of a charity whose function in part is to influence policy and translate policy into services) reflected on how neuroscientific and other studies have influenced the approaches his organization takes:

[Organization] is a very practical, predominately service delivery organization and the main thing that we were trying to bridge with our Early Years Strategy was to take enough of the science to say: yes this seems to have good evidence that this is what we should do and turn it into something practical [...] And was sufficiently linked to the science to say: well, we believe that if we do this then it should put into practice[,] the brain development bit[,] and therefore it will be reasonable to assume that it will have an impact on both parenting but also on baby's brain development. And hopefully in a few years time we will actually start to see tangible benefits from that.

\footnotetext{
During the interviews, and as we have sought to indicate throughout this paper, we were struck by how similar the reflections (including critical comments) of some of our respondents were to those made by social scientists. What does this say about policy engagements with the social sciences, not merely the neurosciences? We might, for instance, want to more broadly and more deeply consider the extent to which communities beyond technoscience are engaging with, drawing upon, reflexively instrumentalizing, and carefully critiquing concepts from STS itself in their work. If, though, some individuals are in fact distant from the academy, yet nevertheless seem to be spontaneously performing 'lay' analysis in ways that evoke the concepts and arguments of social science, what is the distinctive value of specifically social scientific interpretation (cf. Savage and Brown, 2007)?
} 
Respondent 8 expressed something similar when he ended an example of the way brain sciences help thinking about successful adoptions as follows: "In some ways, it doesn't have to be more complicated than that, and we don't like to overcomplicate our learning from the academic world."

Good policy, then, seems to rely on not "overcomplicating" matters through sustained and deep engagement with "the academic world" (Respondent 8). Instead, what is needed is "to take enough of the science" (Respondent 3) to ensure an intervention is in some sense justifiable by appeal to evidence. In an earlier part of the interview, Respondent 8 reflected more on what kind of approach to evidence he took for policymaking:

So I mean, in some ways, [...] I take quite a utilitarian approach to research and evidence. What is it I need to know that will help me to make sense of a policy, which otherwise could have just been driven [...] by gut instinct and good judgement. But how far does good judgment get you without the evidence [...]? [...] [I]f you can't justify using that [approach], then [...] politics will define what your priorities are.

Respondent 3 argued that only by "simplifying the message" will it reach policy and practice:

I think....well I suppose two things, one you have to simplify the message and I think...I initially trained as a scientist and I think the thing as a scientist you're trying to meet scientific standards within your small community, you know what you're talking about. But you have to consciously simplify the message and make it understandable to government, to opinion formers, and I think some scientists don't like that simplification process, because they'll say well with certain caveats this is what the science says. Well actually, no, you need to turn it into a really clear message and say that...and even if it's only 99 per cent true it's effectively true. You have to knock the edges off the message a bit and say: right, this is what we know. And I suppose the other thing is that scientists themselves are not the people usually who are skilled at putting this into practice, they can do the science but then you need passionate people who will say this is really important and this is what we need to do with it and this is how we're going to change things in a practical sense, rather than let scientists go off and say, well more research needs to be done.

Thus, simplification supports a case for change (and not just for more research), in ways that more complicated messages would not. Such quotes can be seen as having similarities with the contingent repertoires analyzed by Gilbert and Mulkay (1982), in that interviewees are reflective of how they pragmatically use research, notwithstanding the empiricist repertoire they adopt in other contexts.

This careful pragmatism also helps in engagement with service users. Respondent 1 talked about the courses for parents she made, arguing:

I think for us what is difficult, and the criticism that we'll get, only from academics, not from anyone else, is that we don't obviously do masses of critical reflection. So, in an academic study you would say, for example, understanding about resilience say, you know that there are internal factors and there's external factors and there's 


\begin{abstract}
organic factors. What we do is condense all the findings and say these are the kind of key findings, right. What we then don't do, is go, but this person thinks it's ridiculous because it doesn't show $\mathrm{x}, \mathrm{y}$ or z...this has only been done with middle class parents or these people think it's not valid because it wasn't done with a controlled group etc. We don't go into that kind of critical reflection, because otherwise we would just confuse people, we're not in an academic context but a real world one.
\end{abstract}

While too much information may confuse parents, presenting the science in a tentative way that still adopts a broadly empiricist framing is also one way of engaging them with parental courses:

When we first started there was a perception that you only engaged with parents' programs if you were a bad parent. What we did through consultation with parents, is we developed this and tried to make it as socially acceptable to attend. Also made it very high level professionally, so it feels like training, so everything is referenced, every single session is referenced with the research, and we're at pains to say, this is one sort of set of findings, or one sort of theory that talks about that. But, in general, the neuroscience, the resilience research, the attachment research, they are all pointing to the same things which is how we interact, how we relate to, how we behave with each other can have massive positive impact. (Respondent 1 )

A more contingent repertoire transforms what could have been a "behavioral management kind of thing" into socially acceptable training, in which the aim is not to "tell people what to $\mathrm{do}^{\prime \prime}$ but to stimulate them to reflect on their parenting practices. Hence, Respondent 1 is involved in creating a balance between, on the one hand, a referenced, professional training in which tentativeness helps to communicate the science (itself an interplay between empiricist and contingent repertoires), and on the other hand a program that does not involve so much tentativeness (and the information that induces this) that participants become confused.

Pragmatic reductionism is not simply a case of always reducing scientific research to its "bare essentials." Rather the form that the reduction takes depends on the imagined audience to which the message will be communicated and expectations regarding their prior knowledge and the uses to which they might put research. Whereas Respondent 1 said that some people did not think "professional concepts" such as attachment should be taught to parents, her experience has been "that parents just lap it up, they absolutely lap it up." Similar to the ways in which the neurosciences are mobilized as a means of aligning "imagined understandings" among policy actors and practitioners, as we have shown above, these quotes show how the neurosciences can also be employed to connect the understandings of practitioners and parents/families.

\title{
Conclusion
}

In this paper, we have analyzed how a range of actors describe the salience of neuroscientific terms, concepts and findings, and account for the use of these in policy and practice within 
Scotland. One of the fundamental problems of democratic societies is intervention: when and how should governmental and other actors intervene in the lives of citizens, and with what rationales? Studying the uses of neuroscience is one way of exploring the problematic of when and how to intervene as well as who (i.e., what kinds of subjects) ought to be governed (cf. Rose, O'Malley, and Valverde 2006; Lemke 2007).

We have shown how the neurosciences are mobilized to legitimize planned policies, substantiate existing policies and services, and expand them (e.g., to attract funding for different target groups, such as babies). In so doing, expectations regarding policy outcomes are directed and consolidated. Scientific research, it seems, is perceived to at once influence the nature of a policy (e.g. by shifting target groups) whilst simultaneously acting as a resource for justifying the mutated policy or service for which there has been advocacy. This suggests an on-going choreography between the design and calibration of policy and services, and engagement with scientific knowledge that is perceived to have novelty, import and authority. In turn, the existence of such a dance implies the need for caution in any claims-making around the extent to which neuroscience "determines" particular social policies or interventions.

Policy actors are frequently targeted by critics for simplifying science, or for failing to understand its nuances. Such criticism, however, elides the "messy complexity of the policy process" (Stevens and Ritter 2013, 169). Further, our data indicate that policy and service advisers and planners might be self-consciously engaged in a form of "pragmatic reductionism" (Beck and Niewöhner 2006, 223), in order to make politically palatable a complex feast of scientific research. They do this so that support and funding can be secured for interventions that they believe will better the lives of citizens.

Accordingly, we suggest that engagements with neuroscience reflect expectations from various actors about both the utility of this body of research in lending epistemic authority to their plans for service design and delivery, as well as hopes around the kinds of citizens, and indeed the kind of world, that will be produced through the instantiation of neurobiological notions within policy. In this sense, an imaginary of the future is mobilized to change the present (Brown 2003). However, such expectations are perhaps somewhat low (though not negative; see Nerlich and Halliday 2007): our interviewees did not appear to consider that neuroscience would help to produce radical improvement in the world, but rather that it would help in small ways to improve particular aspects of the lives of some citizens. This may reflect the same ethic of pragmatism that underpinned the will to reduce the complexity of neuroscience that was evident in some of the interviews (see also Fitzgerald 2014; Gardner, Samuel, and Williams 2015; Pickersgill 2011).

We can see, then, that resonant with the scientists in Gilbert and Mulkay's classic study (1982), individuals involved in social policy and services take findings and concepts from the neurosciences to be (more or less) true and (seek to) mobilize them in policies and interventions; and they are reflexive about how and why neuroscience occupies a place within the ecology of their policy domains. In other words, they often draw on an empiricist discourse whilst also sometimes adopting (and indeed interweaving) a more contingent repertoire. The empiricist-style discourse-which comes, perhaps paradoxically, to be 
positioned within a regime of hope (Moreira and Palladino 2005)—serves important instrumental and symbolic functions (Boswell 2008). While the contingent, reflexive aspect of the respondents' talk could relate in part to the relatively private nature of the sociological interview (Fitzgerald 2014), we argue that our data imply that contingent repertoires can also play an important and explicit public role in, for example, engaging with service users. Assuming such engagements are "successful," we might consider whether neuroscience can be regarded as sparking not just the imaginations of policy actors and service innovators, but also those of the communities they seek to service-connecting these actors together and aligning them around particular goals based on such "mutual imagined understandings" (Martin, Brown, and Kraft 2008, 38). In this light, contingent talk comes to sit most readily within a regime of truth (Moreira and Palladino 2005), and can itself also be instrumentalized.

\section{Acknowledgements}

We are very grateful to two anonymous referees for thoughtful and constructive reflections on this work, as well as to Daniel Lee Kleinman and Katie Vann for their editorial guidance. We would also like to thank Bethany Hipple Walters, Sarah Cunningham-Burley, Ian Deary, our respondents and the Leverhulme Trust.

\section{References}

Beck, S. and J. Niewöhner. 2006. "Somatographic investigations across levels of complexity." BioSocieties 1 (2):219-227.

Bijker, W., R. Bal, and R. Hendriks. 2009. The paradox of scientific authority: The role of scientific advice in democracies. Boston: MIT press.

Bloor, D. 1991. Knowledge and Social Imagery, 2nd Edition. Chicago and London: University of Chicago Press.

Borup, M., N. Brown, K. Konrad, and H. V. Lente. 2006. "The sociology of expectations in science and technology." Technology Analysis \& Strategic Management 18 (3-4):285-298.

Boswell, C. 2008. "The political functions of expert knowledge: knowledge and legitimation in European Union immigration policy." Journal of European Public Policy 15 (4):471-488.

Bröer, C. and M. Heerings. 2013. "Neurobiology in public and private discourse: the case of adults with ADHD." Sociology of Health \& Illness 35 (1):49-65.

Broer, T. and M. Pickersgill. 2015. "Targeting brains, producing responsibilities: the use of neuroscience within British Social Policy." Social Science \& Medicine 132(5): 54-61.

Brown, N. 2003. "Hope against hype: accountability in biopasts, presents and futures." Science Studies 16 (2):3-21.

Brown, N. 2005. "Shifting tenses: reconnecting regimes of truth and hope." Configurations 13 (3):331-355.

Brown, N. and M. Michael. 2003. "A sociology of expectations: retrospecting prospects and prospecting retrospects." Technology Analysis \& Strategic Management 15 (1):3-18. 
Buchman, D., E. Borgelt, L. Whiteley, and J. Illes. 2013. "Neurobiological narratives: experiences of mood disorder through the lens of neuroimaging." Sociology of Health E Illness 35 (1):66-81.

Cairney, P. 2008. "Has Devolution Changed the ‘British Policy Style’?" British Politics 3(3): 350372.

Cairney, P. 2011. "The New British Policy Style: From a British to a Scottish Political Tradition?" Political Studies Review 9 (2): 208-220.

Callon, M. 1986. "Some elements of a sociology of translation: Domestication of the scallops and the fishermen of St. Brieuc Bay." In Power, action, and belief: A new sociology of knowledge, edited by John Law, 196-233. London: Routledge and Kegan Paul.

Choudhury, S., K. A. McKinney, and M. Merten. 2012. "Rebelling against the brain: Public engagement with the 'neurological adolescent'." Social Science \& Medicine 74 (4):565573.

Cohn, S. 2004. "Increasing resolution, intensifying ambiguity: An ethnographic account of seeing life in brain scans." Economy \& Society 33 (1):52-76.

Dumit, J. 2004. Picturing personhood: Brain scans and biomedical identity. Princeton, NJ: Princeton University Press.

Edwards, R., V. Gillies, and N. Horsley. 2015. "Brain science and early years policy: Hopeful ethos or 'cruel optimism'?" Critical Social Policy 35 (2):167-187.

Fitzgerald, D. 2014. "The trouble with brain imaging: Hope, uncertainty and ambivalence in the neuroscience of autism." BioSocieties 9 (3):241-261.

Gardner, J., G. Samuel, and C. Williams. 2015. "Sociology of Low Expectations Recalibration as Innovation Work in Biomedicine." Science, Technology \& Human Values. doi: $10.1177 / 0162243915585579$

Gilbert, N., and M. Mulkay. 1982. "Warranting scientific belief." Social Studies of Science 12 (3):383-408.

Hilgartner, S. 2000. Science on stage: Expert advice as public drama. Stanford, CA: Stanford University Press.

Hilgartner, S. 2012. "Selective flows of knowledge in technoscientific interaction: information control in genome research." The British Journal for the History of Science 45 (2):267-280.

Joyce, K. 2005. "Appealing Images Magnetic Resonance Imaging and the Production of Authoritative Knowledge." Social Studies of Science 35 (3):437-462.

Kerr, A. and S. Cunningham-Burley. 2000. "On ambivalence and risk: reflexive modernity and the new human genetics." Sociology 34 (2):283-304.

Kerr, A., S. Cunningham-Burley, and R. Tutton. 2007. "Exploring ambivalence about genetic research and its social context." Social Theory \& Health 5 (1):53-69.

Lee, E. 2008. "Living with risk in the age of 'intensive motherhood': Maternal identity and infant feeding." Health, Risk \& Society 10 (5):467-477.

Lemke, T. 2007. "An indigestible meal? Foucault, governmentality and state theory." Distinktion: Scandinavian Journal of Social Theory 8 (2):43-64. 
Lowe, P., E. Lee, and J. Macvarish. 2015a. "Biologising parenting: neuroscience discourse, English social and public health policy and understandings of the child." Sociology of Health \& Illness 37(2):198-211.

Lowe, P., E. Lee, and J. Macvarish. 2015b. "Growing better brains? Pregnancy and neuroscience discourses in English social and welfare policies." Health, Risk \& Society (ahead-of-print):1-15.

Macvarish, J., E. Lee, and P. Lowe. 2014. "The 'First Three Years' Movement and the Infant Brain: A Review of Critiques." Sociology Compass 8 (6):792-804.

Macvarish, J., E. Lee, and P. Lowe. 2015. "Neuroscience and family policy: What becomes of the parent?" Critical Social Policy. doi: 10.1177/0261018315574019.

Martin, P., N. Brown, and A. Kraft. 2008. "From bedside to bench? Communities of promise, translational research and the making of blood stem cells." Science as Culture 17 (1):29-41.

Martin, P., N. Brown, and A. Turner. 2008. "Capitalizing hope: the commercial development of umbilical cord blood stem cell banking." New Genetics and Society 27 (2):127-143.

Moreira, T. and P. Palladino. 2005. "Between truth and hope: on Parkinson's disease, neurotransplantation and the production of the 'self'." History of the Human Sciences 18 (3):55-82.

Mulkay, M. 1993. "Rhetorics of hope and fear in the great embryo debate." Social Studies of Science $23(4): 721-742$.

Nerlich, B. and C. Halliday. 2007. "Avian flu: the creation of expectations in the interplay between science and the media." Sociology of Health $\mathcal{E}$ Illness 29 (1):46-65.

O'Connor, C. and H. Joffe. 2013. "Media representations of early human development: Protecting, feeding and loving the developing brain." Social Science \& Medicine 97 (3):297-306.

Pickersgill, M. 2011. "'Promising' therapies: neuroscience, clinical practice, and the treatment of psychopathy." Sociology of Health \& Illness 33(3): 448-464.

Pickersgill, M. 2013. "The social life of the brain." Current Sociology 61(3): 322-340.

Pickersgill, M. 2014. "Neuroscience, epigenetics and the intergenerational transmission of social life: exploring expectations and engagements." Families, Relationships and Societies 3(3): 481-484.

Pickersgill, M., P. Martin, and S. Cunningham-Burley. 2015. "The changing brain: neuroscience and the enduring import of everyday experience." Public Understanding of Science 24(7): 878-892.

Rose, N. 2007. The politics of life itself: Biomedicine, power, and subjectivity in the twenty-first century. Princeton, NJ: Princeton University Press.

Rose, N. and J. M. Abi-Rached. 2013. Neuro: The new brain sciences and the management of the mind. Princeton, NJ: Princeton University Press.

Rose, N., P. O'Malley, and M. Valverde. 2006. "Governmentality." Annual Review of Law and Social Science 2:83-104.

Ross, E. J. (in press). "I think it's self-preservation': risk perception and secrecy in early pregnancy." Health, Risk \& Society 17(5). 
Savage, M. and R. Burrows. 2007. "The coming crisis of empirical sociology." Sociology 41 (5): 885-899.

Shackley, S. and B. Wynne. 1996. "Representing uncertainty in global climate change science and policy: boundary-ordering devices and authority." Science, Technology \& Human Values 21 (3):275-302.

Singh, I. 2013. "Brain talk: power and negotiation in children's discourse about self, brain and behaviour." Sociology of Health E Illness 35 (6):813-827.

Smith, K. E. and S. V. Katikireddi. 2013. "A glossary of theories for understanding policymaking." Journal of epidemiology and community health 67 (2):198-202.

Stevens, A. 2011. "Telling policy stories: an ethnographic study of the use of evidence in policy-making in the UK." Journal of Social Policy 40 (2):237-255.

Stevens, A. and A. Ritter. 2013. "How can and do empirical studies influence drug policies? Narratives and complexity in the use of evidence in policy making." Drugs: Education, Prevention and Policy 20 (3):169-174.

Tutton, R. 2011. "Promising pessimism: reading the futures to be avoided in biotech." Social Studies of Science 41 (3):411-429.

Vidal, F. 2009. "Brainhood, anthropological figure of modernity." History of the Human Sciences 22 (1):5-36.

Vrecko, S. 2010. "Birth of a brain disease: Science, the state and addiction neuropolitics." History of the Human Sciences 23 (4):52-67.

Wall, G. 2004. "Is your child's brain potential maximized? Mothering in an age of new brain research." Atlantis: Critical Studies in Gender, Culture \& Social Justice 28 (2):41-50.

Wall, G. 2010. "Mothers' experiences with intensive parenting and brain development discourse." Women's Studies International Forum 33 (3):253-263.

Wastell, D. and S. White. 2012. "Blinded by neuroscience: Social policy, the family and the infant brain." Families, Relationships and Societies 1 (3):397-414.

Williams, S. J., P. Higgs, and S. Katz. 2012. "Neuroculture, active ageing and the 'older brain': problems, promises and prospects." Sociology of Health \& Illness 34 (1):64-78. 